\title{
INCIDENCE AND OUTCOMES OF PATIENTS WITH PERI-PROCEDURAL CREATINE KINASE (CK-MB) ELEVATION
}

\author{
S SRINIVASA REDDY GUNDAM, K.S.S.SAIBABA.
}

\begin{abstract}
:
Aims: Peri-procedural myocardial infarction (MI) is not an uncommon complication of percutaneous coronary intervention (PCI). We investigated the incidence and clinical outcomes of patients with peri-procedural creatine kinase elevation over one year followup.

Methods: We prospectively evaluated the consecutive patients undergoing PCI either with acute coronary syndrome (ACS) or chronic stable angina (CSA) as presentation in our unit from July 2014 to December 2015. The term enzymatic infarct (EI) is used to include all patients with peri-procedural CK-MB elevation more than upper limit of normal (ULN). These patients are divided into three categories based on level of enzyme elevation and type of presentation. Type A includes those with CK-MB between 1 to 3 times the ULN, type B includes true peri-procedural MI that means $C K-M B>3$ times ULN, type C includes patients with baseline CK-MB elevation due to acute MI. We used the PMI definition from the third universal definition of $\mathrm{MI}$ : creatine kinase $(\mathrm{CK}-\mathrm{MB})>3$ times upper limit of normal. We followed them up to one year for the major adverse cardiovascular events (MACES) and other complications. We compared the mortality rate between periprocedural enzymatic infarct group and non peri-procedural enzymatic infarct patients along with incidence of periprocedural EI in CSA versus ACS subgroups and tested for the significance.

Results: Out of total 748 patients who undergone PCI in our unit, the total incidence of peri-procedural EI was $7.7 \%$. Among total 58 peri-procedural EI events, 23(3\%) were in patients with ACS presentation ( $p=0.001)$ and $34(4.5 \%)$ were in patients with CSA presentation $(p=0.0001)$. Patients with periprocedural EI had significantly higher risk of mortality than those without peri-procedural EI $(5.1 \%$ versus $0.2 \%, p=$ 0.001).In subgroup analysis among patients with periprocedural EI the mortality is higher in patients with ACS presentation compared to those with CSA as presentation $(8.6 \%$ versus $2.9 \%(p=0.01))$, and the total mortality is confined to the type B enzymatic infarct group.
\end{abstract}

Article received on $10^{\text {th }}$ July 2016, published on $30^{\text {th }}$ July 2016.

S. Srinivas Reddy Gundem ${ }^{1}$, KSS Sai baba ${ }^{2}$

${ }^{1}$ Senior resident, Department of Cardiology, NIMS, India

${ }^{2}$ Professor of Biochemistry, NIMS.

Corresponding author: S.Srinivas Reddy Gundem ${ }^{1}$,

Email :dr.gssr.mbbs@gmail.com
Conclusion: Among patients undergoing PCI, the occurrence of peri-procedural EI measured by CK-MB mass assay was $7.7 \%$ and Peri-procedural EI type B was associated with significant increase in mortality over one year followup.

Keywords: Percutaneous coronary intervention, Myocardial infarction, Mortality, Enzymatic infarct

\section{INTRODUCTION}

Percutaneous coronary intervention (PCI) is an established strategy for the management of obstructive coronary artery disease since past four decades. Now we have to concentrate on factors which are responsible for the outcome of these procedures to give good public health. Percutaneous coronary intervention can be associated with a small but significant incidence of several peri-procedural complications such as myocardial infarction (MI), thrombosis, stroke, major bleeding, or death. Among these events, the long term outcome of peri-procedural MI, which can range from a minor elevation of cardiac enzymes to a large-sized infarct, is not clear from the existing studies $[1,2]$. We aimed to study the outcome of peri-procedural MI patients at one year when compared to those patients who did not had in this DES era.

\section{MATERIALS \& METHODS}

We have retrospectively analyzed the data of 748 patients presenting with obstructive CAD undergoing PCI in our unit of Cardiology, from July 2014 to December 2015. We included both the stable and unstable coronary artery disease patients in our study. We excluded patients with significant renal, hepatic and other systemic dysfunction and patients who are in severe cardiogenic shock. Institutional ethical committee approval was taken. Informed consent was taken from all the patients before inclusion into the study. All patients were evaluated after a detailed history, physical examination, and appropriate investigations. Demographic and clinical characteristics of patients were documented. 
PCI was performed according to current standard guidelines. Antiplatelet therapy and peri-procedural anticoagulation were administered according to standard regimens. All patients were pre-treated with oral aspirin and Clopidogrel or Prasugrel or Ticagrelor 2-6 h prior to the procedure and glycoprotein IIb/IIIa inhibitor or Bivalirudin is used in accordance with the discretion of the operator. PCI were done through radial or femoral route as per operator's choice. All patients undergoing PCI were given $70 \mathrm{IU} / \mathrm{kg}$ unfractionated heparin before PCI, while drug eluting stents were deployed in all the patients. Dual antiplatelet therapy was recommended post-PCI at least for 1 year.

All the patients were classified according to their angiographic profile as single vessel disease $(>70 \%$ lesion involving one epicardial coronary artery) or multi vessel disease $(>70 \%$ stenosis in 2 or more epicardial coronary arteries). Angiographic success was defined as residual coronary artery stenosis $<20 \%$ after stent implantation with TIMI grade 3 flow. ECGs were taken immediately after the procedure and after 24 hours to look for any fresh changes.

Routine measurements of CK-MB, as measured by mass assay, were performed in all patients $[3,4,5]$. CK-MB Mass assay was performed with the immunochemical method as implemented on the ACS-180 analyzer Blood samples were routinely collected for the measurement of CK-MB levels at baseline, every $8 \mathrm{~h}$ for the first $24 \mathrm{~h}$ after the procedure. For each patient, the CK-MB ratio was calculated as the ratio between the peak CK-MB level and the upper limit of normal. Routine measurements of cardiac troponin after PCI were not performed. All laboratory testing was performed by personnel who were blinded to the patient information and study objectives.

The term enzymatic infarct (EI) is used to include all patients with peri-procedural CK-MB elevation more than upper limit of normal. These patients are divided into three categories based on level of enzyme elevation and type of presentation. Type A includes those with CK-MB between 1 to 3 times the ULN, type B includes true peri-procedural $\mathrm{MI}$ that means $\mathrm{CK}-\mathrm{MB}>3$ times ULN, type C includes patients with baseline CK-MB elevation due to acute MI.

Peri-procedural EI was defined as an elevation of CK$\mathrm{MB}$ more than upper limit of the normal range in at least two blood samples with a normal range of baseline value within 48 hours of the procedure. If the pre-PCI CK-MB values are elevated more than the upper normal limits, such as patients initially presented with acute MI, CK-MB re-elevation at least $50 \%$ greater than the most recent pre-procedure concentration with documentation that the values were stable or falling before PCI was required for the diagnosis of peri-procedural $\mathrm{MI}$ in this setting.

\section{FOLLOW UP:}

Clinical follow-up was performed via clinic visit or telephone contact at 1, 6 and 12 months.At each time of follow-up contact, data pertaining to patients' clinical status and interim occurrence of adverse events were collected.

\section{STATISTICAL ANALYSIS:}

Data analysis was performed using Minitab version 16 software. Continuous variables were expressed as mean \pm SD. Baseline parameters were compared between groups using the Student $t$ test for continuous variables and the chi-square test for categorical variables. Results with a $\mathrm{p}$ value $<0.05$ is considered to be significant.

\section{RESULTS}

We analyzed data from 748 patients presenting with CAD undergoing PCI from our Cardiology unit of a tertiary care center in southern India (the Nizam's Institute of Medical Sciences, Hyderabad) from July 2014 to December 2015. The baseline characteristics, clinical presentation, angiographic profile and outcomes were given in Table1. Out of total 748 patients who undergone $\mathrm{PCI}$ in our unit, the total incidence of peri-procedural EI was $7.7 \%$. Among total 58 peri-procedural EI events, 30 were in type A, 24 in type B and 4 in type C category, and $23(3 \%)$ were in patients with ACS as presentation $(p=0.001)$ and $34(4.5 \%)$ were in patients with CSA as presentation $(\mathrm{p}=0.0001)$. Men are more involved in both groups than women. In the present study the incidence of diabetes is more in non peri-procedural EI group compared to peri-procedural EI group $(71.7 \%$ vs $53.4 \%$, $\mathrm{p}=0.007)$. 
Table 1: Baseline characteristics of patients according to peri-procedural enzymatic infarction.

\begin{tabular}{|c|c|c|c|}
\hline Variables & $\begin{array}{l}\text { PEI group } \\
(\mathrm{n}=58)\end{array}$ & $\begin{array}{l}\text { Non-PEI } \\
\operatorname{group}(n=690 \\
)\end{array}$ & $\begin{array}{l}\mathrm{p} \\
\text { value }\end{array}$ \\
\hline No of patients & 58 & 690 & \\
\hline Female: Male & 14: 44 & 180: 510 & \\
\hline Age (Yrs) & $56.9 \pm 12.2$ & $57.9 \pm 11.1$ & 0.6 \\
\hline HTN & $33(56.9 \%)$ & $459(66.5 \%)$ & 0.2 \\
\hline $\mathrm{DM}$ & $31(53.4 \%)$ & $495(71.7 \%)$ & 0.007 \\
\hline SM & $12(20.7 \%)$ & $159(23.04 \%)$ & 0.7 \\
\hline \multicolumn{4}{|l|}{ Type Of Pres.: ACS } \\
\hline & $24(41.3 \%)$ & $218(18.6 \%)$ & 0.001 \\
\hline CSA & $34(59.7 \%)$ & $506(81.4)$ & \\
\hline LV Dysfunction & $37(63.8 \%)$ & $134(19.4 \%)$ & 0.0001 \\
\hline Previous PCI & $8(13.8 \%)$ & $33(19.3 \%)$ & 0.3 \\
\hline Post CABG & $2(0.3 \%)$ & 0 & 0.2 \\
\hline Multivessel & $17(29.3 \%)$ & $204(29.6 \%)$ & 0.96 \\
\hline \multicolumn{4}{|l|}{ Route of PCI: Radial } \\
\hline & $44(75.9 \%)$ & $576(83.5 \%)$ & 0.2 \\
\hline $\begin{array}{l}\text { Complex Lesion (B2 \& } \\
\text { C) }\end{array}$ & $51(87.9 \%)$ & $588(85.2 \%)$ & 0.6 \\
\hline $\begin{array}{l}\text { Leuc.Count(cells/cu.mm } \\
\text { ) }\end{array}$ & $10929 \pm 8594$ & $9054 \pm 4019$ & 0.02 \\
\hline Hemoglobin $(\mathrm{g} / \mathrm{dl})$ & $13.2 \pm 2.1$ & $12.98 \pm 2.1$ & 0.4 \\
\hline Blood urea(mg/dl) & $33.1 \pm 16.3$ & $28.5 \pm 15.3$ & 0.04 \\
\hline Creatinine(g/dl) & $1.2 \pm 0.4$ & $1.2 \pm 0.7$ & 0.9 \\
\hline Pre-Ref.Vess.Dia (mm) & $2.5 \pm 0.5$ & $2.4 \pm 0.6$ & 0.3 \\
\hline Pre-MLD (mm) & $1.1 \pm 0.4$ & $1.04 \pm 0.4$ & 0.2 \\
\hline Pre lesion length (mm) & $8.5 \pm 3.9$ & $8.4 \pm 5.6$ & 0.9 \\
\hline Pre stenosis $(\%)$ & $60.2 \pm 14.7$ & $58.5 \pm 13.3$ & 0.4 \\
\hline Post-Ref.Vess.Dia (mm) & $2.9 \pm 0.9$ & $2.7 \pm 0.5$ & 0.001 \\
\hline Post MLD (mm) & $2.3 \pm 0.4$ & $2.2 \pm 0.4$ & 0.06 \\
\hline Stent size $(\mathrm{mm})$ & $2.9 \pm 0.4$ & $2.9 \pm 0.3$ & 0.2 \\
\hline \multirow[t]{2}{*}{ Stent length $(\mathrm{mm})$} & $22 \pm 8.04$ & $21 \pm 8.1$ & 0.4 \\
\hline & $36503 \pm$ & $276 \pm 77.3$ & 0.024 \\
\hline Peak CPK(U/L) & 269257 & & \\
\hline Death at 12 months & $3(5.1 \%)$ & $2(0.2 \%)$ & 0.001 \\
\hline
\end{tabular}

Patients presenting as acute coronary syndromes had higher incidence of peri-procedural EI (41.3\% vs $18.6 \%$, $\mathrm{p}=0.001)$. LV dysfunction was higher in peri-procedural EI group compared to non peri-procedural EI (63.8\% VS $19.3 \%, \mathrm{P}=0.0001$ ).Total leukocyte count and blood urea at presentation were high in peri-procedural EI $\operatorname{group}(\mathrm{p}=0.023, \mathrm{p}=0.042)$. Though the lesion length, stent size and stent length were higher in peri-procedural EI group, they are not statistically significant. Patients with peri-procedural EI had significantly higher risk of mortality than those without peri-procedural EI (5.1\% versus $0.2 \%, p=0.001$ ) (Fig. 1 ).

Fig. 1: Mortality in patients with peri-procedural enzyme elevation with ACS vs CSA presentation

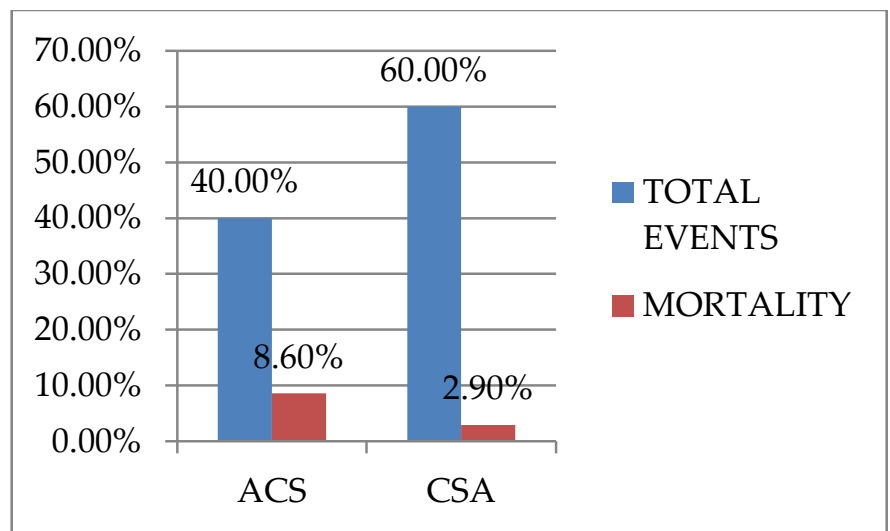

Outcomes of the peri-procedural EI were given in Table2. Out of 23 patients in ACS group 1 had congestive cardiac failure and 2 had sub-acute stent thrombosis. Of total 3 deaths in peri procedural EI, 2 were in ACS group and 1 in CSA group.

Table 2: Outcomes of patients according to periprocedural enzymatic infarction

\begin{tabular}{llll}
\hline Outcomes & $\begin{array}{l}\text { PEI } \\
\text { group } \\
(\mathrm{n}=58)\end{array}$ & $\begin{array}{l}\text { Non PEI } \\
\text { group } \\
(\mathrm{n}=690)\end{array}$ & P value \\
\hline CCF & 1 & 1 & 0.24 \\
\hline Chronic stable angina & 2 & 1 & 0.34 \\
CVA & 1 & 0 & 0.56 \\
\hline Stent thrombosis & 2 & 2 & 0.27 \\
Instent restenosis & 1 & 0 & 0.67 \\
\hline Pseudo aneurysm & 4 & 0 & 0.45 \\
Death & 2 & 3 & 0.001 \\
\hline
\end{tabular}

In subgroup analysis among patients with periprocedural MI the mortality is high in patients with ACS presentation compared to those with CSA as presentation $(8.6 \%$ versus $2.9 \%(\mathrm{p}=0.01))$ (Fig. 1). When the outcomes in three categories of enzymatic infarct group was observed type A had only 1 CSA during 1 year follow up, whereas the total mortality is seen in type $B$ that is true peri-procedural MI with CK-MB 
elevation $>3$ times the ULN. Type C category had no mortality during 1 year follow up (Fig. 2).

Fig. 2: Mortality in peri-procedural enzymatic infarction in all three category patients.

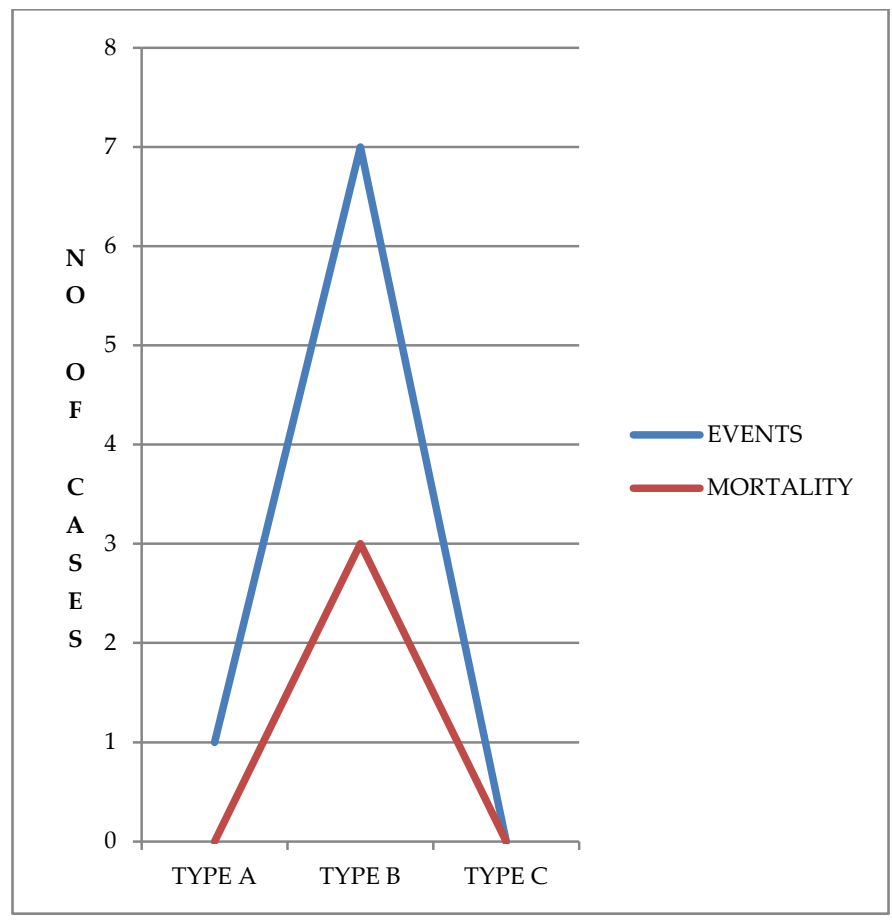

\section{DISCUSSION}

Previous several studies reported that the incidence of peri-procedural MI varies from 5 to $30 \%$ according to the diagnostic criteria and the local practices. After PCI, a number of factors have been associated with periprocedural MI, which can broadly be categorized as patient-related factors, lesion-related factors, and procedure-related factors. Patient-related factors, including multivessel disease, evidence of systemic atherosclerosis, reduced left ventricular ejection fraction, diabetes mellitus, older age, and chronic kidney disease, increase the risk of post procedural CK-MB release by 1.3- to 1.8-fold[6, 7, 8]. Systemic inflammation on presentation including elevated

hs-C-reactive protein correlates with post procedural CK-MB elevation, as does an elevated admission white cell count $(9.5 \times 106 / \mathrm{L})$. The clinical syndrome on presentation also affects risk, with enzyme negative patients with acute coronary syndromes (ACS) having up to a $40 \%$ incidence of post-PCI enzyme elevations and enzyme-positive ACS patients having even more frequent and larger post procedural MIs. Lesion-related factors $[9,10]$ such as disease burden, calcification, lesion eccentricity, and thrombus predict increased peri procedural enzyme release. Procedure-related variables such as device selection, in particular, atherectomy; aggressive stent expansion resulting in plaque extrusion, side branch occlusion, and side branch stenting; and angiographic complications including distal embolization, coronary dissection, no-reflow, vasospasm, and unsuccessful procedures, are all associated with peri procedural MI.

In totality, these risk factors identify patients with increasing atherosclerotic disease burden, increased thrombotic risk, and with neuro-hormonal activation, that predisposes to either macrovascular complications (side branch occlusion or macro-embolization) or microvascular obstruction (distal embolization of microparticles), unifying the pathophysiologic basis of myocardial necrosis after PCI. The controversy is whether peri-procedural biomarker elevations are independent predictors of subsequent mortality or merely represent underlying comorbidities and diffuse atherosclerosis. There have been several investigations regarding criteria, risk factors, and impact of periprocedural MI on outcome. However, the clinical relevance and long-term prognostic value still remain a matter of considerable debate. The purpose of the present study was to determine the frequency, causes, and risk factors of peri-procedural EI and to assess the relationship between peri-procedural EI and mortality. Park et al. have presented a comprehensive analysis of the incidence, mechanisms, risk factors, and relationship to outcomes of PMI following PCI [11]. It is the largest study, in which CK-MB mass assay was routinely performed in all patients, to systematically evaluate the frequency, causes, predictors, and clinical relevance of peri-procedural MI using patient-level data from several PCI trials. The major findings are (i) the overall incidence of peri-procedural MI was 7\%; (ii) side-branch occlusion is the most common cause, and there was no identifiable mechanical cause in one-fifth; (iii) several higher risk clinical, angiographic, and procedural features were identified as independent predictors; (iv) peri-procedural MI was associated with an increased risk of mortality.

In our study, the overall incidence of peri-procedural EI was $7.75 \%$, and true peri-procedural MI (type B) is $3.2 \%$ which was less than the expected range of previous PCI 
studies using the same CK-MB criteria. Recent consensus documents support that the preferred biomarker for myocardial necrosis is cardiac troponin (I or T), which has high myocardial tissue specificity as well as high clinical sensitivity [12, 13]. With its increased sensitivity, compared with CK-MB measurement, the use of cardiac troponin might significantly increase the prevalence of peri-procedural MI [14, 15]. Several studies showed that measurement of troponin indeed resulted in a doubling or tripling of the rate of diagnosis of MI. However, until now, there is less experience using this biomarker and it may be overly sensitive for discriminating prognostic impact. In the upcoming years, the specificity for PCI-related coronary events and prognostic relevance of troponin should be confirmed through large clinical trials, and also its increased sensitivity has to be carefully weighed against the reduced specificity for device-specific outcomes. There is limited support in the literature for determining the relative frequency of plausible mechanisms based on large datasets with solid angiographic documentations. Previous study suggested that the adverse effect of any MI on mortality was confined to patients with evident angiographic complications, not those without angiographic complications [16]. Therefore, it warrants further studies to determine whether additional monitoring or management is indicated for isolated CKMB elevation without obvious angiographic complications.

There are conflicting data regarding the prognostic relevance of peri-procedural MI [17]. In our study, periprocedural EI (type B ) was associated with an increased risk of morality. However, we cannot address whether peri-procedural MI has direct causality for mortality or it functions as a marker of more severe coronary atherosclerosis and procedural complexity that is responsible for higher mortality after PCI. Meanwhile, in clinical viewpoint, the presence of peri-procedural MI would be used to be an important biomarker descriptor identifying high-risk patients for future clinical events.

In previous study, the incidence of peri-procedural MI was significantly lower in patients with acute coronary syndrome than in those with stable angina (6.3 vs. $8.2 \%$, $\mathrm{P}, 0.001)$. But in our study the incidence was significantly low in patients with stable angina than those with acute coronary syndrome (6.7 vs 9.9\%).Since most cases of NSTEMI or STEMI involve PCI during a period when biomarkers are increasing, a reliable distinction between subsequent MI and index MI event is very difficult in clinical practice. Therefore, to define a second MI for such individuals, clearer guidelines and diagnostic criteria remain to be established. If other mandatory criteria of ischaemic, angiographic, or imaging findings of third definition of MI, which are not currently available in this data sets, are simultaneously applied, the prevalence of MI would be further decreased, but the prognostic influence would be more intensified. Further studies are needed to verify the clinical utility and prognostic value of newer definitions of MI among diverse PCI settings.

We have limitations to this study. 1) It is a study from a single center which is prone to different bias and not a randomized control trial so that we can't draw any conclusions from the study. 2) We didn't study the mechanism of peri-procedural MI.

\section{CONCLUSIONS}

Among patients undergoing PCI, the occurrence of periprocedural EI measured by CK-MB mass assay was $7.7 \%$ and true peri-procedural MI (type B EI )was associated with significant increase in mortality over one year follow-up.

\section{REFERENCES}

1. Babu GG, Walker JM, Yellon DM, Hausenloy DJ. Periprocedural myocardial injury during percutaneous coronary intervention: an important target for cardioprotection.Eur Heart J 2011;32:23-31.

2. Prasad A, Herrmann J. Myocardial infarction due to percutaneous coronary intervention.NEngl J Med 2011;364:453-464.

3. Mair J, Artner-Dworzak E, Dienstl A, Lechleitner P, Morass B, Smidt J, Wagner I, Wettach C, Puschendorf B. Early detection of acute myocardial infarction by measurement of mass concentration of creatine kinaseMB. Am J Cardiol. 1991;68:1545-1550.

4. Grenadier E, Keidar S, Kahana L, Alpan G, Marmur A, Palant A. The roles of serum myoglobin, total CPK, and CK-MB isoenzyme in the acute phase of myocardial infarction. Am Heart J. 1983;105:408-416. 
5. Gerhardt W, Katus H, Ravkilde J, Hamm C, Jorgensen PJ, Peheim E, Ljungdahl L, Lofdahl P. S-troponin T in suspected ischemic myocardial injury compared with mass and catalytic concentrations of S-creatine kinase isoenzyme MB. Clin Chem. 1991;37:1405-1411.

6. Roe MT, Mahaffey KW, Kilaru R, Alexander JH, Akkerhuis KM, Simoons ML, et al. Creatine kinase-MB elevation after percutaneous coronary intervention predicts adverse outcomes in patients with acute coronary syndromes. Eur Heart J. 2004;25:313-321.

7. Lansky AJ, Goto K, Cristea E, Fahy M, Parise H, et al. Clinical and angiographic predictors of short- and longterm ischemic events in acute coronary syndromes: results from the Acute Catheterization and Urgent Intervention Triage strategY (ACUITY) Trial. CircCardiovascInterv. 2010;3:308 -316.

8. Ellis SG, Chew D, Chan A, Whitlow PL, Schneider JP, Topol EJ. Death following creatine kinase-MB elevation after coronary intervention: identification of an early risk period: importance of creatine kinase-MB level, completeness of revascularization, ventricular function, and probable benefit of statin therapy. Circulation. 2002;106:1205-1210.

9. Mehran R, Dangas G, Mintz GS, Lansky AJ, Pichard $\mathrm{AD}$, Satler LF, Kent KM, Stone GW, Leon MB. Atherosclerotic plaque burden and CK-MB enzyme elevation after coronary interventions : intravascular ultrasound study of 2256 patients. Circulation. 2000;101:604-610.

10. Kanaparti PK, Brown DL. Relation between coronary atherosclerotic plaque burden and cardiac enzyme elevation following percutaneous coronary intervention.Am J Cardiol. 2000;86:619-622.

11. Park DW, Kim YH, Yun SC, Ahn JM, Lee JY, Kim WJ, Kang SJ, Lee SW et al. Frequency, causes, predictors, and clinical significance of peri-procedural myocardial infarction following percutaneous coronary intervention. Eur Heart J. 2013 Jun;34(22):1662-9.

12.KristianThygesen, Joseph S. Alpert, Allan S. Jaffe, Maarten L. Simoons, Bernard R. Chaitman, Harvey D.
White, Bolger, et al. Third universal definitionof myocardial infarction. Eur Heart J 2012;33:2551-2567.

13. Thygesen K, Alpert JS, White HD, Jaffe AS, Apple FS, Galvani M, Katus HA, et al. Universal definitionof myocardial infarction. Circulation 2007;116:2634-2653.

14. Serruys PW, Silber S, Garg S, van Geuns RJ, Richardt $\mathrm{G}$, et al. Comparison of zotarolimus-eluting and everolimus-eluting coronary stents. $\mathrm{N}$ Engl J Med2010;363:136-146.

15. Lim CC, van Gaal WJ, Testa L, Cuculi F, Arnold JR, et al. With the 'universal definition', measurement of creatine kinase-myocardial band rather than troponin allows more accurate diagnosis of periprocedural necrosis and infarction after coronary intervention. J Am CollCardiol2011;57:653-661

16.Jeremias A, Baim DS, Ho KK, Chauhan M, Carrozza JP Jr, Cohen DJ, Popma JJ, Kuntz RE, Cutlip DE. Differential mortality risk of postprocedural creatinekinase-MB elevation following successful versus unsuccessful stent procedures. J Am Coll Cardiol2004;44:1210-1214.

17. Lindsey JB, Kennedy KF, Stolker JM, Gilchrist IC, Mukherjee D, Marso SP,Pencina MJ, Kleiman NS, Cohen DJ. Prognostic implications of creatine kinase-MB elevation after percutaneous coronary intervention: results from the Evaluation of Drug-Eluting Stents and Ischemic Events (EVENT) registry. CircCardiovascInterv2011;4:474-480. 